\title{
The effect of pre-release captivity on post-release performance in reintroduced eastern bettongs Bettongia gaimardi
}

\author{
William G. Batson, Iain J. Gordon, Donald B. Fletcher \\ and ADRIAN D. MANNING
}

\begin{abstract}
Reintroductions are used to re-establish populations of species within their indigenous range, but their outcomes are variable. A key decision when developing a reintroduction strategy is whether to include a temporary period of confinement prior to release. Pre-release confinement is primarily used for the purpose of quarantine or as a delayed-release tactic to influence the performance or behaviour of founders post-release. A common difference between these approaches is that quarantine tends to be conducted in ex situ captivity, whereas delayed releases tend to involve in situ confinement at the release site. Although these practices are commonly viewed independently, it may be possible for a single confinement period to be used for both purposes. We tested whether temporarily holding wild eastern bettongs Bettongia gaimardi in ex situ captivity for $95-345$ days prior to release (delayed release) influenced their body mass, pouch occupancy or survival during the first 1.5 years post-release, compared to founders released without confinement (immediate release). Our results suggest that exposing founders to captivity did not alter their body mass or performance post-release, despite being heavier and having fewer pouch young when released. We conclude that, for this species, ex situ captivity does not represent a tactical opportunity to improve post-release performance but can be used for quarantine without affecting the probability of establishment.
\end{abstract}

Keywords Australia, Bettongia gaimardi, quarantine, reintroduction, release protocol, release strategy, Tasmanian bettong

\footnotetext{
William G. Batson (Corresponding author) and Adrian D. Manning The Fenner School of Environment and Society, The Australian National University, Building 41, Linnaeus Way, Canberra, ACT 2601, Australia.

E-mail william.batson@anu.edu.au

IAIN J. GoRDON* The James Hutton Institute, Invergowrie, Dundee, Scotland

Donald B. Fletcher Environment and Planning Directorate, ACT Government, Canberra, Australia

${ }^{*}$ Also at: The Fenner School of Environment and Society, The Australian National University, Canberra, Australia

Received 12 November 2014. Revision requested 3o January 2015.

Accepted 1 April 2015. First published online 11 August 2015.
}

\section{Introduction}

The objective of a reintroduction is to re-establish a 1 population of a species within its indigenous range (Seddon, 2010; IUCN/SSC, 2013); globally many reintroductions have taken place but the outcomes of these projects are variable (Soorae, 2008, 2010, 2011, 2013). A variety of tactics can be incorporated into a reintroduction process to improve the performance (e.g. survival, reproduction) and behaviour (e.g. settlement and dispersal) of the founder population post-release (Batson et al., 2015). Other tactics can be used to manage the ecological risks associated with reintroductions, including quarantine to avoid detrimental disease and co-introductions of pathogens or parasites (Woodford, 2000). Aspects of a reintroduction that are focused at a population level are usually viewed independently from those focused on the ecosystem (Armstrong \& Seddon, 2008). However, certain tactics can induce responses across these ecological levels, and improving our understanding of these could improve the quality and efficiency of reintroduction strategies.

The selection of release tactics is usually defined as a choice between a delayed release, when founders are housed in situ at the release site temporarily prior to release, and an immediate release, with no pre-release confinement (Parker et al., 2012). These are described as soft and hard release, respectively (Wanless et al., 2002; Mitchell et al., 2011), but these terms are considered inappropriate unless the effect on the severity of transition into the recipient environment is known (Parker et al., 2012; Moseby et al., 2014, Batson et al., 2015). Delayed release can improve the probability of establishment by allowing founders to recover, acclimatize, establish social relationships and become familiar with their surroundings prior to release (Bright \& Morris, 1994; Gusset et al., 2006; Mitchell et al., 2011). However, adopting this approach can have a detrimental effect by increasing mortality, stress and injury, especially in wild animals (Christensen \& Burrows, 1994; Linklater et al., 2010; Richardson et al., 2015). In other situations the release tactic used has no effect on the probability of establishment (Castro et al., 1994; Lovegrove, 1996; Hardman \& Moro, 2006), which makes immediate release preferable on the grounds of reduced cost (Hardman \& Moro, 2006).

The variability of responses to release tactics inhibits the ability to make sweeping recommendations regarding the most appropriate approach when faced with uncertainty 
(Parker et al., 2012). However, some general recommendations are provided for certain reintroduction contexts, including the use of delayed releases for captive-bred birds, and immediate releases for wild birds, based on their familiarity and reaction to confinement (Jones \& Merton, 2012). The ability to make general recommendations will improve through the accumulation of experimental evidence, highlighting the value of conducting reintroductions within experimental frameworks to test the effectiveness of methodological variations (Armstrong et al., 1994; Moseby et al., 2014; Kemp et al., 2015).

All translocations present a risk that novel organisms will be co-introduced to the recipient environment, and managing this risk should be a key consideration when developing translocation strategies (IUCN/SSC, 2013). Quarantine is often used to manage this risk, and is often conducted within specialist captive facilities that provide the required level of isolation (Woodford, 200o). Although quarantine is used primarily to manage ecological risks it can also induce biological, behavioural or physiological responses in founder populations; for example, exposing European rabbits Oryctolagus cuniculus to quarantine generally improves their body condition but causes females to abort reproduction (Calvete et al., 2005). As quarantine can affect the performance of translocated wildlife, these effects must be considered carefully when developing translocation strategies.

Many reintroductions include both ex situ quarantine and in situ confinement to obtain population and ecosystem benefits (e.g. McClelland \& Gummer, 2006; Cid et al., 2014; Kenyon et al., 2014). However, in certain situations it may be possible to use ex situ captivity to achieve multiple benefits, including managing ecological risk and improving the probability of establishment; for example, wild Canada lynx Lynx canadensis showed an improved rate of post-release survival after being held temporarily in ex situ captivity (Devineau et al., 2011), with this period presumably also presenting the opportunity to conduct quarantine if required. The ability to use a single period of confinement to serve both benefits has obvious attractions, as multiple confinement periods invariably increase the financial cost (Karesh, 1993; Henri et al., 2004).

We investigated whether housing wild eastern bettongs Bettongia gaimardi in ex situ captivity for 95-345 days prior to release influences their body mass, survival and pouch occupancy during the initial 1.5 years post-release, compared with those exposed to an immediate release. Based on our results we provide practical recommendations regarding the use of ex situ captivity in subsequent reintroductions. We also tested whether the performance of the founders differed from our pre-release expectations, to assess the effect of the reintroduction and to evaluate postrelease establishment. This study focused on the founder population at Mulligans Flat Woodland Sanctuary, in the
Australian Capital Territory, released during 2012. This reintroduction represents the first attempt to re-establish eastern bettongs on the Australian mainland following a 100-year absence (Short, 1998), and is a component of a large-scale experiment aiming to restore biological integrity and ecological function to a critically threatened woodland community (Manning et al., 2011; Shorthouse et al., 2012).

\section{Study areas and species}

Tidbinbilla Nature Reserve is located in rural Australian Capital Territory and is owned and operated by the territory government. The Reserve is a certified member of the Zoo and Aquarium Association and operates captive breeding programmes for various threatened species, including northern corroboree frogs Pseudophryne pengilleyi and southern brush-tailed rock-wallabies Petrogale penicillata. A permanent insurance population of eastern bettongs was also established at the Reserve, which housed the delayed-release group during the pre-release confinement period. Bettongs were predominantly housed within 2.6-9.4 ha enclosures, with small groups $(<5)$ housed in smaller enclosures (0.5-1 ha) during an initial 30-day quarantine and during trials. The composition of the groups within each enclosure was managed to ensure that reproduction could only occur among individuals from different regions in Tasmania (Fig. 1). A specialized on-site veterinary centre was used to conduct all health assessments (Portas et al., 2014). All enclosures were protected by electrified fences and were not accessible by the public. Food (fruits, vegetables, nuts, seeds and proteins) and water were provided daily ad libitum. All enclosures included natural vegetation suitable for bettongs to make diurnal nests and for natural foraging behaviour.

Mulligans Flat Woodland Sanctuary is a publicly accessible area within Mulligans Flat Nature Reserve, adjacent to the northern suburbs of Canberra, and is co-managed by the Woodlands and Wetlands Trust and the Australian Capital Territory government. It is c. $60 \mathrm{~km}$ from Tidbinbilla Nature Reserve. The Sanctuary encompasses 485 ha of critically threatened mixed yellow-box Eucalyptus melliodora and Blakely's red gum Eucalyptus blakelyi grassy woodland (McIntyre et al., 2010), enclosed by a barrier fence against foxes, cats and dogs, which have been eradicated from the internal area. The Sanctuary is considered an outdoor laboratory and is the location of the Mulligans FlatGoorooyarroo Woodland Experiment (Manning et al., 2011; Shorthouse et al., 2012). The bettong population is treated as wild, with no husbandry management or supplementary resources provided. Bettongs have complete access to the Sanctuary, except for 12 1-ha sites that are fenced to facilitate assessment of the ecological effect of bettong diggings. 


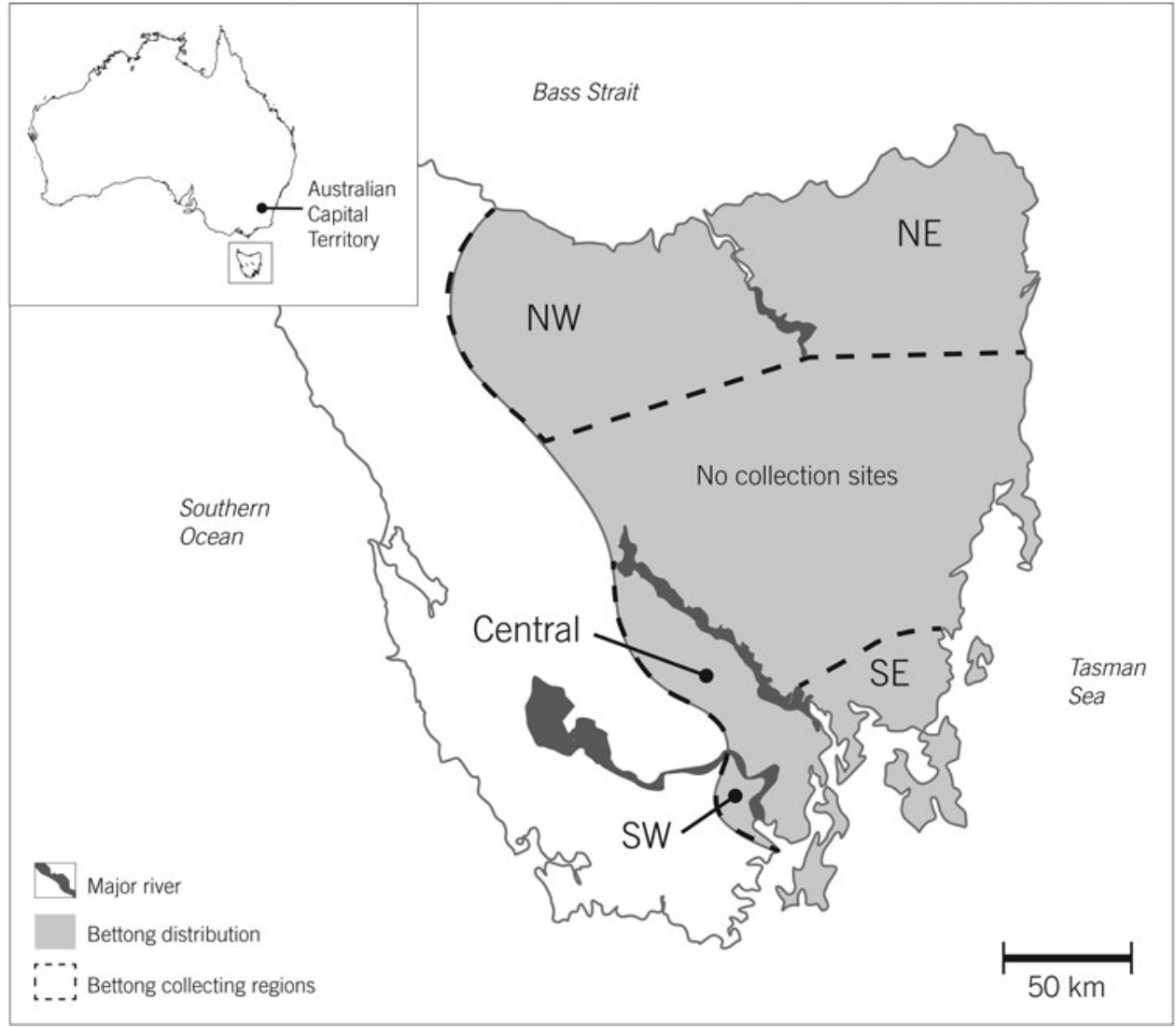

FIg. 1 Regions of Tasmania where eastern bettongs Bettongia gaimardi in free-ranging populations were trapped for reintroduction in Australian Capital Territory. As a precaution, each region was assumed to be genetically isolated by geographical barriers (e.g. major rivers).
Eastern bettongs (also known as Tasmanian bettongs) are nocturnal, ground dwelling, mycophagous marsupials that occupy various woodland and forest habitats (Taylor, 1993a,b; Johnson, 1994). Females reach sexual maturity at c. 9 months of age and are capable of near-continuous breeding (Rose, 1987). Once common throughout eastern mainland Australia, their distribution is now restricted to eastern Tasmania (Fig. 1) and the species is categorized as Near Threatened on the IUCN Red List (Menkhorst, 2008). Disease transmission from feral cats has been implicated as a cause of a recent population decline (Fancourt, 2014). Bettongs dig soil when foraging and are therefore considered to be ecosystem engineers, and their reintroduction may help to re-establish diminished ecological processes (Fleming et al., 2014; Manning et al., 2015).

\section{Methods}

\section{The translocation process}

Sixty adults (19 male, 41 female) and their 28 pouch young were translocated from Tasmania to the Australian Capital Territory in four collection events during July 2011September 2012 (Table 1). Bettongs were collected from wild populations from five geographical areas in Tasmania to increase genetic diversity (Fig. 1). Subadults, females carrying furred pouch young, and females with elongated teats were excluded from the translocation. A female-biased sex ratio was established to increase post-translocation population growth, and the pouches of females carrying pouch young were taped to prevent ejection. Once selected for translocation each individual was weighed and administered diazepam to act as a mild sedative, before being transported by road and air to Tidbinbilla Nature Reserve, where they arrived within 18 hours of acquisition. A second dose of diazepam was administered immediately before air transportation. Upon arrival each individual was anaesthetized, fitted with a passive integrated transponder tag, and given a full health assessment by a qualified veterinarian, which included measurements of body mass, pes (foot) length, tail width, head length and ectoparasite load, and classifications of body condition (using a subjective assessment of fat stores around hips), tooth wear and coat condition. Rectal, urogenital, conjunctival and nasal tract swabs and blood samples were collected to evaluate pathogen history and endoparasite load, and ear biopsies were collected for genetic analyses. The head length and sex of pouch young were also assessed. No food or water was provided during the translocation process but saline was administrated intravenously if required. Portas et al. (2014) provide further details regarding the translocation process and health assessments. 


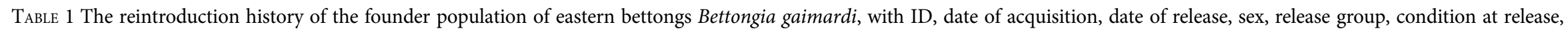
mortality, origin (Fig. 1), and the number of times each individual was trapped during acquisition, release, and 1-60, 61-180, 181-360 and 361-540 days post-release.

\begin{tabular}{|c|c|c|c|c|c|c|c|c|c|c|c|c|c|}
\hline ID & $\begin{array}{l}\text { Date of } \\
\text { acquisition }\end{array}$ & $\begin{array}{l}\text { Date of } \\
\text { release }\end{array}$ & Sex & Group & $\begin{array}{l}\text { Condition } \\
\text { at release }\end{array}$ & Mortality & Origin & Acquisition & Release & $\begin{array}{l}\text { Days } \\
1-60\end{array}$ & $\begin{array}{l}\text { Days } \\
61-180\end{array}$ & $\begin{array}{l}\text { Days } \\
181-360\end{array}$ & $\begin{array}{l}\text { Days } \\
361-540\end{array}$ \\
\hline 9607 & 28 May 2012 & 28 May 2012 & $\mathrm{~F}$ & Immediate & Good & No & Central & 1 & 1 & 1 & 1 & 0 & 1 \\
\hline $0 \mathrm{~A} 3 \mathrm{E}$ & 3 Sep. 2012 & 3 Sep. 2012 & $\mathrm{~F}$ & Immediate & Fair & No & NW & 1 & 1 & 1 & 1 & 2 & 1 \\
\hline $1 \mathrm{~F} 8 \mathrm{~A}$ & 28 May 2012 & 28 May 2012 & $\mathrm{M}$ & Immediate & Good & No & Central & 1 & 1 & 1 & 3 & 1 & 2 \\
\hline A3F5 & 1 June 2012 & 1 June 2012 & M & Immediate & Good & No & SW & 1 & 1 & 2 & 1 & 3 & 6 \\
\hline A5F0 & 30 May 2012 & 30 May 2012 & $\mathrm{M}$ & Immediate & Good & No & SE & 1 & 1 & 3 & 1 & 3 & 2 \\
\hline BB1E & 30 May 2012 & 30 May 2012 & $\mathrm{~F}$ & Immediate & Good & No & SE & 1 & 1 & 1 & 2 & 1 & 1 \\
\hline BFD1 & 5 Sep. 2012 & 5 Sep. 2012 & $\mathrm{M}$ & Immediate & Good & No & $\mathrm{NE}$ & 1 & 1 & 1 & 0 & 0 & 1 \\
\hline C1F5 & 31 May 2012 & 31 May 2012 & $\mathrm{~F}$ & Immediate & Good & Misadventure $(20)^{\star}$ & SW & 1 & 1 & 1 & 1 & 0 & 0 \\
\hline C38E & 30 May 2012 & 30 May 2012 & $\mathrm{~F}$ & Immediate & Good & No & SE & 1 & 1 & 2 & 1 & 1 & 2 \\
\hline $\mathrm{C} 5 \mathrm{~A} 3$ & 3 Sep. 2012 & 3 Sep. 2012 & $\mathrm{M}$ & Immediate & Fair & No & NW & 1 & 1 & 1 & 0 & 3 & 2 \\
\hline CC1D & 31 May 2012 & 31 May 2012 & $\mathrm{~F}$ & Immediate & Good & No & SW & 1 & 1 & 2 & 1 & 1 & 3 \\
\hline $\mathrm{CD} 42$ & 31 May 2012 & 31 May 2012 & $\mathrm{M}$ & Immediate & Good & No & SW & 1 & 1 & 2 & 2 & 3 & 4 \\
\hline CFC1 & 3 Sep. 2012 & 3 Sep. 2012 & $\mathrm{~F}$ & Immediate & Good & No & NW & 1 & 1 & 1 & 0 & 2 & 2 \\
\hline DE28 & 5 Sep. 2012 & 5 Sep. 2012 & $\mathrm{~F}$ & Immediate & Fair & No & $\mathrm{NE}$ & 1 & 1 & 0 & 3 & 1 & 1 \\
\hline F271 & 5 Sep. 2012 & 5 Sep. 2012 & $\mathrm{~F}$ & Immediate & Fair & Health condition $(33-35)^{*}$ & $\mathrm{NE}$ & 1 & 1 & 1 & 0 & 0 & 0 \\
\hline F88D & 28 May 2012 & 28 May 2012 & $\mathrm{~F}$ & Immediate & Good & No & Central & 1 & 1 & 1 & 1 & 0 & 1 \\
\hline 3643 & 7 June 2011 & 17 May 2012 & $\mathrm{~F}$ & Delayed & Excellent & No & SW & 1 & 1 & 1 & 1 & 2 & 2 \\
\hline 7E03 & 27 May 2012 & 23 Aug. 2012 & $\mathrm{M}$ & Delayed & Good & No & Central & 1 & 1 & 0 & 0 & 0 & 1 \\
\hline 8906 & 27 Oct. 2011 & 4 Sep. 2012 & $\mathrm{~F}$ & Delayed & Excellent & Health condition $(0)^{*}$ & NW & 1 & 1 & 0 & 0 & 0 & 0 \\
\hline 9475 & 26 Oct. 2011 & 3 Sep. 2012 & $\mathrm{~F}$ & Delayed & Good & No & NW & 1 & 1 & 1 & 0 & 0 & 1 \\
\hline 895D & 26 Oct. 2011 & 3 May 2012 & $\mathrm{~F}$ & Delayed & Good & No & NW & 1 & 1 & 1 & 2 & 1 & 4 \\
\hline 9F8A & 24 Oct. 2011 & 26 Apr. 2012 & $\mathrm{~F}$ & Delayed & Good & No & $\mathrm{NE}$ & 1 & 1 & 2 & 1 & 2 & 3 \\
\hline B401 & 25 Oct. 2011 & 4 Sep. 2012 & $\mathrm{~F}$ & Delayed & Excellent & No & $\mathrm{NE}$ & 1 & 1 & 1 & 0 & 0 & 0 \\
\hline B5F9 & 28 Oct. 2011 & 3 May 2012 & $\mathrm{M}$ & Delayed & Excellent & No & NW & 1 & 1 & 1 & 3 & 3 & 3 \\
\hline C728 & 24 Oct. 2011 & 17 May 2012 & $\mathrm{~F}$ & Delayed & Good & No & $\mathrm{NE}$ & 1 & 1 & 2 & 1 & 2 & 1 \\
\hline CAB1 & 28 May 2012 & 4 Sep. 2012 & $\mathrm{~F}$ & Delayed & Excellent & No & Central & 1 & 1 & 1 & 1 & 6 & 4 \\
\hline $\mathrm{D} 4 \mathrm{AC}$ & 25 Oct. 2011 & 26 Apr. 2012 & $\mathrm{~F}$ & Delayed & Good & Misadventure $(13)^{\star}$ & $\mathrm{NE}$ & 1 & 1 & 1 & 0 & 0 & 0 \\
\hline E578 & 24 Oct. 2011 & 22 Aug. 2012 & $\mathrm{~F}$ & Delayed & Excellent & Health condition $(332-336)^{*}$ & $\mathrm{NE}$ & 1 & 1 & 1 & 0 & 1 & 0 \\
\hline EBAD & 30 May 2012 & 3 Sep. 2012 & M & Delayed & Good & No & SW & 1 & 1 & 1 & 0 & 4 & 2 \\
\hline $\mathrm{F} 4 \mathrm{BC}$ & 29 May 2012 & 3 Sep. 2012 & $\mathrm{M}$ & Delayed & Good & No & SE & 1 & 1 & 2 & 0 & 2 & 1 \\
\hline F68E & 25 Oct. 2011 & 26 Apr. 2012 & M & Delayed & Good & No & $\mathrm{NE}$ & 1 & 1 & 1 & 1 & 3 & 3 \\
\hline F823 & 26 Oct. 2011 & 3 May 2012 & $\mathrm{~F}$ & Delayed & Excellent & No & NW & 1 & 1 & 1 & 1 & 2 & 3 \\
\hline
\end{tabular}

${ }^{\star}$ The number in parentheses indicates the timing of mortality in terms of number of days post-release. 
Upon arrival each bettong was assigned at random to a population (Tidbinbilla Nature Reserve or Mulligans Flat Woodland Sanctuary) but those with health conditions were kept permanently at the Reserve. Pouch young stayed with their mothers throughout the translocation. Twentyeight adults were assigned to the permanent captive population at the Reserve. The remaining 32 adults were assigned to the wild population at the Sanctuary, with 16 (11 female) in the delayed-release group (i.e. housed at the Reserve prior to release at the Sanctuary), and 16 (10 female) in the immediate-release group. Following the completion of the initial health assessments those assigned to the delayedrelease group were released into small enclosures at the Reserve for a 30-day quarantine period. Following a postquarantine health assessment members of this group were moved to the large enclosures, where they remained until their transfer to the Sanctuary. Upon completion of the 95-345 day confinement period bettongs were transferred to the Sanctuary in similar sized groups as the immediaterelease group (Table 1), and released at similar times. Members of the immediate-release group were transferred and released at the Sanctuary following the completion of the heath assessment at the Reserve on the day of translocation. All immediate releases occurred within 24 hours of initial acquisition in Tasmania.

\section{Post-release monitoring}

Thirty-one founders were fitted with VHF (V5C_161C; Sirtrack, Hawkes Bay, New Zealand) or global positioning system (GPS)/VHF radio collars (Q40ooE; Telemetry Solutions, Walnut Creek, USA) when released. One individual was not collared because of a neck injury. Each collar weighed $28-32 \mathrm{~g}$, which is $<2.5 \%$ of the body mass of the lightest individual released. The collars transmitted a continuous VHF pulse, and a mortality signal was activated following 12 hours without movement. The post-release survival of each individual was monitored daily for 1 month post-release, and thereafter at least weekly until the collar was removed after 1 year. If a mortality signal was detected the collar was located immediately to determine the cause. On one occasion a collar was removed because of injury, and four collars detached accidentally. Three of the detached collars were reattached before the completion of the monitoring period. Necropsies were conducted on all deceased individuals (Portas et al., 2014).

Post-release health assessments were scheduled to occur at 1, 3, 6 and 12 months post-release but the timing and frequency varied because of logistical constraints (Table 1). To trap bettongs for a scheduled health assessment we radiotracked each individual of interest to its daytime nest and deployed six traps in close proximity. The health assessment included measurements of body mass, pes length and tail width, assessment of body condition, and measurement of the head length of pouch young. The assessments were conducted without sedation but with procedures in place to minimize handling time, which was generally $<10$ minutes. The pouches of females carrying unfused pouch young were taped to reduce the risk of pouch ejection (the tape detaches within a few hours). Individuals were released at the point of capture upon completion of the health assessment. When non-target individuals were captured they were either given a full health assessment or were weighed and released, depending on the proximity to their scheduled health assessment. In total, 218 capture events were recorded during the monitoring period.

\section{Statistical methods}

All statistical analyses were conducted using SPSS v. 22 (IBM, Armonk, USA), with significance assumed at $\mathrm{P}<0.05$.

Body mass We used body mass as a proxy for body condition (sensu Moseby et al., 2014). We opted not to use a body condition index (e.g. Hardman \& Moro, 2006) because of the lack of correlation between pes length and body mass in our data $\left(R^{2}<0.1\right)$. The body mass of females with occupied pouches was adjusted by subtracting the estimated mass of the pouch young. This was calculated using the quadratic equation for estimating the age of a pouch young from its head length and an exponential equation to estimate its mass from its estimated age, as described by Rose (1989). We excluded the body mass of females carrying pouch young from the analysis if the head length of the pouch young was not recorded. The records were divided into the following periods: acquisition, data collected during translocations from Tasmania; release, data collected when individuals were released at the Sanctuary (synonymous with acquisition for the immediate-release group); days $1-60$, data collected $1-60$ days post-release; days $61-180$, data collected $61-180$ days post-release; days $181-360$, data collected $181-360$ days post-release; days $361-540$, data collected 361-540 days post-release. To minimize the effect of repeated measures we used the mean body mass of any individual captured multiple times within a period, which reduced the dataset to 143 samples. We compared the body mass of the two groups using a linear mixed model with time and group as factors (using a compound symmetry correlation structure), with release as the starting point. We conducted randomization tests to assess whether body mass within the two groups was different within each period. This process was similar to that used by Moseby et al. (2014). We did not differentiate between sexes because of the lack of sexual dimorphism (Rose, 1989; Claridge et al., 2007). We compared the post-release body mass of the entire population against our pre-release expectation, using a 
randomization test. Our expectation was set according to the body mass at acquisition $(\tilde{x}=1,629 \pm$ SD $176 \mathrm{~g})$.

Pouch occupancy Pouch occupancy was assessed by visually inspecting the pouches of females during health assessments. A pouch was considered occupied if a pouch young was observed in the pouch or in the trap with the adult. The data were organized into the periods described above, with samples excluded if the pouch young had been recorded previously, based on the expected growth rate and a 106-day pouch life (Rose, 1989). It was possible for multiple pouch young to be recorded from a single female within a period when pouch young were replaced between health assessments. The proportions of pouch occupancy of the two groups were compared for each period using Fisher's exact test. This approach was also used to assess whether postrelease pouch occupancy for the entire population differed from our pre-release expectation, which was set at 0.71 , representing the proportion observed at acquisition. We confirmed that all delayed-released females had access to potential mates at the Reserve within 106 days of release, to ensure that pouch inactivity was not attributable to lack of mating opportunities.

Survival No meaningful statistical comparison of survival between the two groups was possible because of the low number of mortalities, and therefore only descriptive accounts are presented. We tested whether the mortality rate observed during the first year post-release differed from the expected rate of 0.2 per annum using Fisher's exact test. The expected mortality rate was based on the maximum life expectancy of 6 years (Rose, 1987), and the ages of founders randomly falling between 1 and 6 years when released. This assumption was used because the ages at acquisition could not be estimated accurately, with the minimum age being based on the exclusion of non-mature individuals at acquisition. The analysis was restricted to the first year post-release because the status of all individuals was known following completion of this period, although some of the evidence for this was outside the data set used during this study.

\section{Results}

The linear mixed effect model indicated there was no significant difference between the body mass of the two groups $\left(F_{1,30}=0.161, \mathrm{P}=0.691\right)$. However, the body mass of founders was influenced by time $\left(F_{4,88}=4.674, \mathrm{P}=0.002\right)$, and there was a significant interaction between time and treatment $\left(F_{4,88}=6.999, \mathrm{P}<0.001\right)$. These results reflect that the delayed-release group was heavier when released, and the extra mass was lost soon after release, before stabilizing, whereas the immediate-release group maintained consistent body mass across the monitoring period. The randomization tests confirmed that the only significant difference between the two groups was at release $(\mathrm{P}<0.001)$, although the difference approached significance at acquisition $(\mathrm{P}=0.1)$. Overall, the post-release body masses recorded at the Sanctuary exceeded our initial expectation $(\mathrm{P}=0.005)$, indicating that the body mass of the whole population increased significantly post-release (Fig. 2).

The proportion of pouch occupancy was greater in the immediate-release group compared to the delayed-release group at release $(\mathrm{P}=0.03)$, with no other significant between-group differences occurring within any other period (Fig. 3). Overall, the rate of post-release pouch occupancy differed significantly from the expected rate $(\mathrm{P}=0.01)$, indicating that the reproductive activity of females was higher at the Sanctuary compared to the source populations in Tasmania. Two pouch young were known to be lost between sampling events prior to the expected 106 day pouch life, and pouch occupancy was recorded in all surviving females within 6 months of release.

Five mortalities were recorded during the monitoring period. All deceased bettongs were female; three were members of the delayed-release group (Table 1). Necropsies confirmed that three of the mortalities resulted from preexisting health conditions (two in the delayed-release group), with the remaining deaths being attributed to misadventure. The timing of two of the mortalities may have been influenced by the reintroduction process, given the temporal proximity to release: a member of the delayedrelease group did not recover from being anaesthetized on the day of release, and a member of the immediate-release group died c. 1 month post-release. Overall, the mortality rate observed during the first year post-release was 0.16 , which did not differ significantly from the expected mortality rate of $0.2(\mathrm{P}=1)$.

\section{Discussion}

Our results suggest that exposing founders to ex situ captivity did not influence the body mass, pouch occupancy or survival of the founder group within any period post-release for the bettongs released at the Sanctuary. This is despite the delayed-release group being significantly heavier $(+10 \%)$ and having a lower rate of pouch occupancy ( 27 vs $80 \%$ ) than the immediate-release group when released. Overall, this indicates pre-release captivity does not represent a viable release tactic for improving the performance of founders post-release, unless it induces a positive behavioural response, which was not assessed in this study.

The lack of a significant effect on post-release survival is consistent with the results of similar studies involving translocated macropods (family Macropodidae); for example, implementing delayed and immediate releases did not affect post-release survival in burrowing bettongs Bettongia lesueur, greater bilbies Macrotis lagotis (Moseby et al., 2014) 


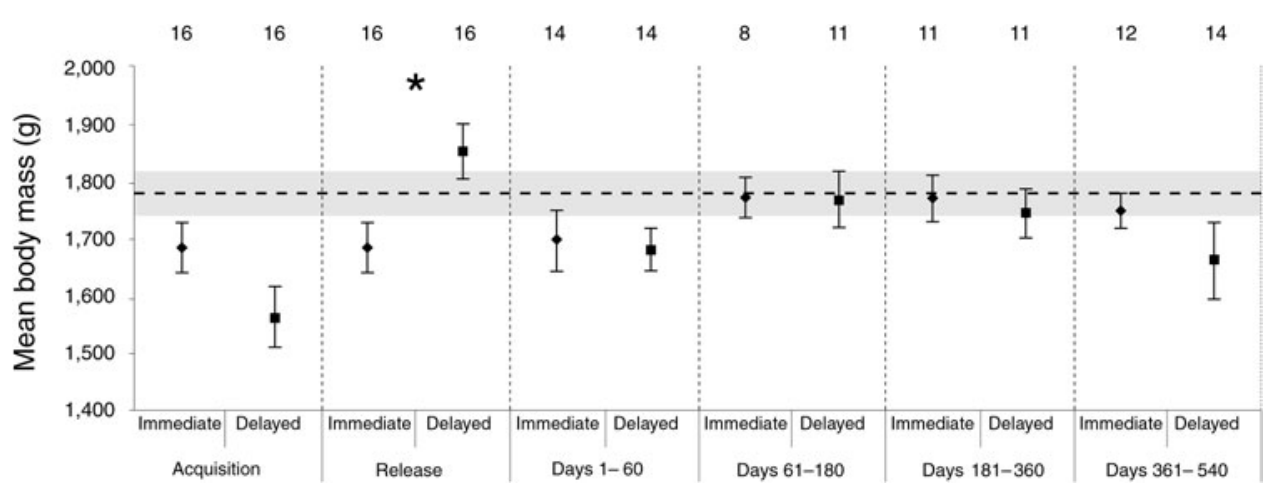

FIG. 2 The mean body mass of bettongs in each release group within six sampling periods: acquisition, release, and 1-6o, $61-180,181-360$ and $361-540$ days post-release. The numbers above the data points represent the number of individuals sampled, and the asterisk represents a significant difference between the groups. Error bars represent \pm 1 SE. The horizontal line represents the expected body mass based on that recorded at acquisition, with the shaded area representing $\pm_{1} \mathrm{SE}$.

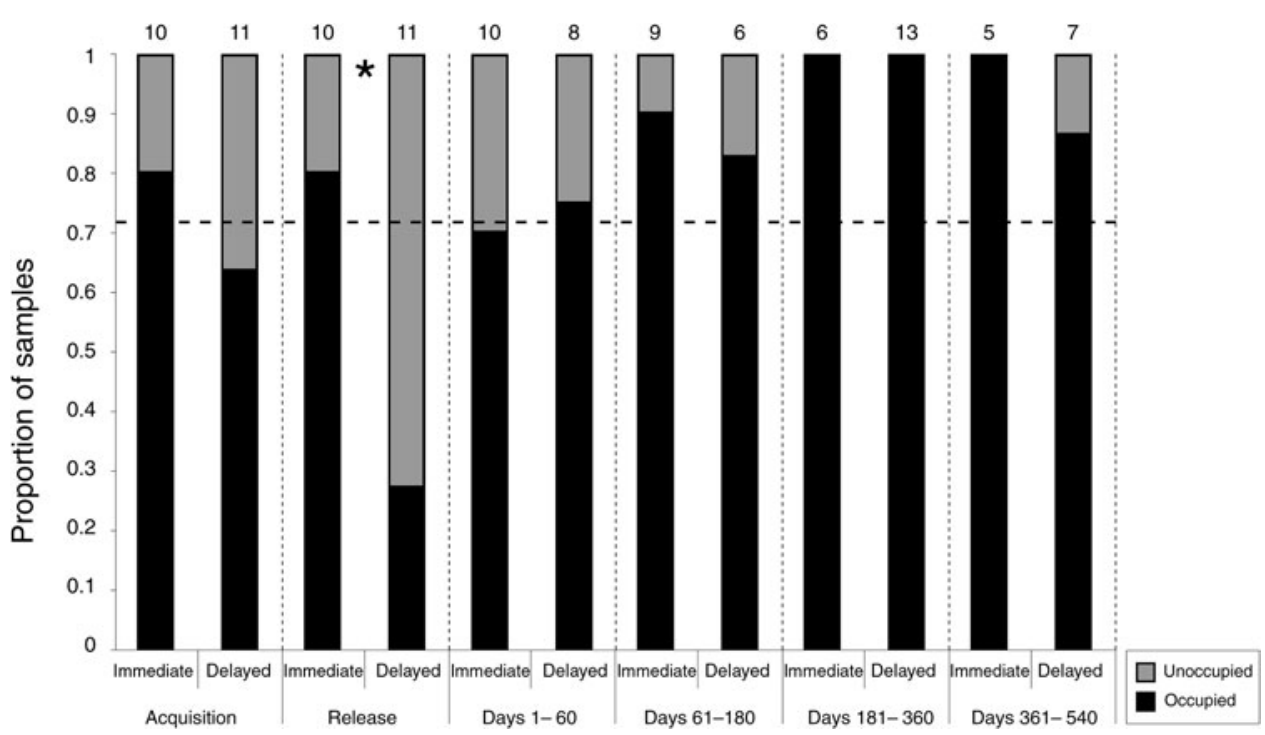

FIG. 3 The rate of pouch occupancy recorded in each group within the six sampling periods. The numbers above the bars represent the number of individuals sampled, and the asterisk represents a significant difference between the groups. The horizontal line represents the expected rate of pouch occupancy based on the rate recorded at acquisition.

or banded Lagostrophus fasciatus and rufous hare-wallabies Lagorchestes hirsutus (Hardman \& Moro, 2006). As these studies involved wild and captive-bred macropods, it appears that the life history of founders does not alter the survival response to various release tactics, which contrasts with the general trend observed in birds, whereby survival is generally higher when captive-bred birds are exposed to a delayed release, and the converse is true for certain species of wild birds (Mitchell et al., 2011; Jones \& Merton, 2012; Richardson et al., 2015). As many of the macropod studies have been conducted in the absence of exotic predators (e.g. this study; Moseby et al., 2014), and involved small experimental groups (e.g. Hardman \& Moro, 2006; Moseby et al., 2014), the effect of release tactics on predation vulnerability needs to be assessed before robust conclusions regarding reintroductions to wild sites can be drawn.
Our results suggest that captivity had a negative effect on reproduction, although near-continuous breeding has been achieved in another captive population of eastern bettongs (Rose, 1987). The variability of captive pouch occupancy may indicate that reproduction is primarily affected when wild bettongs are temporarily exposed to captivity, or that there is a specific cause at Tidbinbilla Nature Reserve, with obesity, diet, stress and human-determined mate-choice providing possible explanations (Kleiman et al., 2010; Michel \& Bonnet, 2012). The reduction of pouch occupancy at release needs to be considered when developing reintroduction strategies for eastern bettongs because it will increase the lag time to post-release recruitment. However, as every surviving female was observed to be reproductively active within 6 months of release, the initial reduced proportion of pouch occupancy 
is unlikely to affect the long-term genetic viability (Jamieson \& Lacy, 2012).

The body mass advantage of the delayed-release group at release was not maintained, with no significant differences detected post-release. Moseby et al. (2014) observed a similar trend in burrowing bettongs, although the delayedrelease group was still relatively heavier 2 weeks after release, partly because the immediate-release group lost weight during that period. Although an immediate weight loss was not detected in the immediate-release animals in our study, it may have occurred without being detected, given the frequency of trapping events. Overall, it appears that the body mass of translocated bettongs (eastern and burrowing) is determined primarily by environmental surroundings, and that the relative body mass at release has only a shortterm effect. This also suggests that temporarily exposing wild bettongs to captivity does not influence their ability to acquire resources once released back into the wild.

The body mass and rate of pouch occupancy in the founder group post-release exceeded our expectation, whereas post-release survival was consistent with the expected rate. However, as $80 \%$ of the mortalities recorded appear to have been influenced by the translocation process or post-release monitoring, survival at the Sanctuary could also be considered to have exceeded the expected rate. The performance of the founder group reflects the suitability of the habitat, low levels of competition, and absence of exotic predators at the Sanctuary, and provides evidence that the founder group transitioned successfully through the establishment phase of a reintroduction (Armstrong \& Seddon, 2008; IUCN/SSC, 2013). This is also supported by the recruitment of new individuals at the Sanctuary. Given the favourable conditions at the Sanctuary it is likely that the body mass and performance recorded in the founder group were near-optimal for a wild population, which provides a useful comparison to evaluate the condition of other populations.

The lack of a significant biological response to varying release tactics is consistent with the general outcomes of other studies involving reintroduced macropods, using in situ captivity for delayed release (Hardman \& Moro, 2006; Moseby et al., 2014). In addition to the effects on body mass, survival and reproduction, release tactics were also found to have no effect on settlement or dispersal in greater bilbies (Moseby et al., 2014) or banded and rufous harewallabies (Hardman \& Moro, 2006) despite influencing settlement in burrowing bettongs (Moseby et al., 2014). As delayed release did not provide a significant establishment benefit we would recommend immediate release to increase resource efficiency if pre-release quarantine was not required. This conclusion is consistent with the prediction of the conceptual model presented by Moseby et al. (2014), based on the behavioural characteristics (sociality, site fidelity and ranging) of eastern bettongs and the environmental characteristics (fencing and predation risk) of Mulligans Flat Woodland Sanctuary.

Despite the lack of significant effects detected in macropod studies, the popularity of delayed releases appears to be increasing (Clayton et al., 2014). This suggests that the designs of these reintroductions are based on perceived benefits rather than experimental evidence, which is a common feature of reintroductions (Parker et al., 2012). However, implementing a delayed release can provide a number of nonbiological benefits. During this reintroduction the delayed release facilitated quarantine, ecological risk assessments (Portas et al., 2014), and equipment trials prior to release. The use of both release tactics within a structured framework spread the risk of failure by exposing founders to various methods, and facilitated experimental investigation of the responses to these variations. The delayed release also provided an opportunity for the bettongs that were translocated from Tasmania in poor condition to increase their body mass prior to release. Although many of the nonbiological benefits could have been provided by in situ confinement, the use of ex situ captivity avoided the need to build new infrastructure, and the delayed-release group could be managed by professional staff as part of the daily operations at the Reserve.

We acknowledge that the strength of our statistical analyses is restricted by the small number of individuals, which is common in reintroduction biology (Seddon et al., 2007). We also accept that the probability of success was high because of the lack of predators at the Sanctuary, and the barrier to dispersal (Short et al., 1992; Clayton et al., 2014). However, low-risk reintroduction often represents the most appropriate environment to test the effectiveness of various methodologies, because predation and dispersal can mask subtle effects. The results of such experiments can then be used to develop new hypotheses and improve the quality of reintroduction strategies for releases into higher-risk environments. One of the strengths of this study is that it assessed the responses to release tactics over a prolonged period, which is sometimes essential to detect an effect (e.g. Richardson et al., 2015).

Based on our results we recommend selecting release tactics based on evaluations of financial cost and ecological risk rather than the assumed effect on establishment. However, effects on stress, settlement, dispersal and vulnerability to predation need to be assessed before a robust conclusion can be drawn. If the risk of detrimental co-introduction is considered high in subsequent reintroductions, we advocate the use of a delayed release involving ex situ captivity as an appropriate form of quarantine, because of its minimal effect on establishment probabilities. We also recommend this approach when these ecological risks are unknown, as a precaution. However, if the ecological risks are considered low then an immediate release should be used to maximize cost efficiency. 


\section{Acknowledgements}

The translocation was carried out under license from the Tasmanian Department of Primary Industries, Parks, Water and Environment (DPIPWE) using procedures approved by their associated Ethics Committee (AEC Project 18/2010-2011). We thank DPIPWE for their support. The post-reintroduction procedures were approved by the Australian National University Animal Experimentation Ethics Committee (ethics protocol A2011/o17). WB was supported by a PhD scholarship funded through an Australian Research Council Linkage Grant (LP110100126). ADM was supported by an Australian Research Council Future Fellowship (FT100100358). This project was conducted as part of the Mulligans Flat-Goorooyarroo Woodland Experiment. We thank Helen Crisp, Jenny Newport, Nicola Munro, Tim Portas, Claire Wimpenny, Scott Ryan, David Dobroszczyk, Elyce Fraser, Ani Kunz, Andrea Reiss, Nick Mooney, Matthew Pauza, Peter Mills, Daniel Iglesias, Grant Woodbridge, John Lawler, Stuart Jefferies, David Shorthouse, Ross Cunningham, Jeff Wood, Christopher Johnson and Margret Kitchin for their assistance during the project. We thank Bob Forrester for his advice on statistics, and two anonymous reviewers for their valuable feedback.

\section{References}

Armstrong, D.P. \& Seddon, P.J. (2008) Directions in reintroduction biology. Trends in Ecology \& Evolution, 23, 20-25.

Armstrong, D.P., Soderquist, T. \& Southgate, R. (1994) Designing experimental reintroductions as experiments. In Reintroduction Biology of Australian and New Zealand Fauna (ed. M. Serena), pp. 27-29. Surrey Beatty \& Sons, Chipping Norton, Australia.

Batson, W.G., Aввотt, R. \& Richardson, K.M. (2015) Release strategies for fauna reintroductions: theory and tests. In Advances in Reintroduction Biology of Australian and New Zealand Fauna (eds D.P. Armstrong, M.W. Hayward, D. Moro \& P.J. Seddon), pp. 7-16. CSIRO Publishing, Collingwood, Australia.

Bright, P.W. \& Morris, P.A. (1994) Animal translocation for conservation: performance of dormice in relation to release methods, origin and season. Journal of Applied Ecology, 31, 699-708.

Calvete, C., Angulo, E., Estrada, R., Moreno, S. \& Villafuerte, R. (2005) Quarantine length and survival of translocated European wild rabbits. The Journal of Wildlife Management, 69, 1063-1072.

Castro, I., Alley, J.C., Empson, R.A. \& Minot, E.O. (1994) Translocation of hihi or stitchbird Notiomystis cincta to Kapiti Island New Zealand: transfer techniques and comparison of release strategies. In Reintroduction Biology of Australian and New Zealand Fauna (ed. M. Serena), pp. 113-120. Surrey Beatty \& Sons, Chipping Norton, Australia.

Christensen, P.E.S. \& Burrows, N. (1994) Project desert dreaming: experimental reintroduction of mammals to the Gibson Desert, Western Australia. In Reintroduction Biology of Australian and New Zealand Fauna (ed. M. Serena), pp. 199-207. Surrey Beatty \& Sons, Chipping Norton, Australia.
Cid, B., Figueira, L., Mello, A.F.T., Pires, A.S. \& Fernandez, F.A.S. (2014) Short-term success in the reintroduction of the red-humped agouti Dasyprocta leporina, an important seed disperser, in a Brazilian Atlantic Forest reserve. Tropical Conservation Science, 7 , 796-810.

Claridge, A.W., Seebeck, J. \& Rose, R.W. (2007) Bettongs, Potoroos and the Musky Rat-Kangaroo. CSIRO Publishing, Collingwood, Australia.

Clayton, J.A., Pavey, C.R., Vernes, K. \& Tighe, M. (2014) Review and analysis of Australian macropod translocations 1969-2006. Mammal Review, 44, 109-123.

Devineau, O., Shenk, T.M., Doherty, P.F., White, G.C. \& Kahn, R.H. (2011) Assessing release protocols for Canada lynx reintroduction in Colorado. The Journal of Wildlife Management, 75, 623-630.

Fancourt, B.A. (2014) Rapid decline in detections of the Tasmanian bettong (Bettongia gaimardi) following local incursion of feral cats (Felis catus). Australian Mammalogy, 36, 247-253.

Fleming, P.A., Anderson, H., Prendergast, A.S., Bretz, M.R., Valentine, L.E. \& Hardy, G.E.S. (2014) Is the loss of Australian digging mammals contributing to a deterioration in ecosystem function? Mammal Review, 44, 94-108.

Gusset, M., Slotow, R. \& Somers, M.J. (2006) Divided we fail: the importance of social integration for the re-introduction of endangered African wild dogs (Lycaon pictus). Journal of Zoology, $270,502-511$.

Hardman, B. \& Moro, D. (2006) Optimising reintroduction success by delayed dispersal: is the release protocol important for hare-wallabies? Biological Conservation, 128, 403-411.

Henri, K., Milne, G.R. \& Shah, N.J. (2004) Costs of ecosystem restoration on islands in Seychelles. Ocean \& Coastal Management, $47,409-428$.

IUCN/SSC (2013) Guidelines for Reintroductions and other Conservation Translocations. IUCN Species Survival Commission, Gland, Switzerland.

Jamieson, I.G. \& LACY, R.C. (2012) Managing genetic issues in reintroduction biology. In Reintroduction Biology: Integrating Science and Management (eds J.G. Ewen, D.P. Armstrong, K.A. Parker \& P.J. Seddon), pp. 441-475. Wiley-Blackwell, Oxford, UK.

Johnson, C.N. (1994) Nutritional ecology of a mycophagous marsupial in relation to production of hypogeous fungi. Ecology, 75, 2015-2021.

Jones, C.G. \& Merton, D.V. (2012) A tale of two islands: the rescue and recovery of endemic birds in New Zealand and Mauritius. In Reintroduction Biology: Integrating Science and Management (eds J.G. Ewen, D.P. Armstrong, K.A. Parker \& P.J. Seddon), pp. 33-72. Wiley-Blackwell, Oxford, UK.

KARESH, W.B. (1993) Cost evaluation of infectious disease monitoring and screening programs for wildlife translocation and reintroduction. Journal of Zoo and Wildlife Medicine, 24, 291-295.

Kemp, L., Norbury, G., Groenewegen, R. \& Comer, S. (2015) The roles of trials and experiments in fauna reintroduction programs. In Advances in Reintroduction Biology of Australian and New Zealand Fauna (eds D.P. Armstrong, M.W. Hayward, D. Moro \& P.J. Seddon), pp. 73-90. CSIRO Publishing, Collingwood, Australia.

Kenyon, M., Streicher, U., Loung, H., Tran, T., Tran, M., Vo, B. \& Cronin, A. (2014) Survival of reintroduced pygmy slow loris Nycticebus pygmaeus in South Vietnam. Endangered Species Research, 25, 185-195.

Kleiman, D.G., Thompson, K.V. \& Baer, C.K. (eds) (2010) Wild Mammals in Captivity: Principles and Techniques for Zoo Management. The University of Chicago Press, Chicago, USA.

Linklater, W.L., MacDonald, E.A., Flamand, J.R.B. \& Czekala, N.M. (2010) Declining and low fecal corticoids are associated with 
distress, not acclimation to stress, during the translocation of African rhinoceros. Animal Conservation, 13, 104-111.

Lovegrove, T.G. (1996) Island releases of saddlebacks Philesturnus carunculatus in New Zealand. Biological Conservation, 77, 151-157.

Manning, A., Wood, J., Cunningham, R., McIntyre, S., Shorthouse, D., Gordon, I. \& Lindenmayer, D. (2011) Integrating research and restoration: the establishment of a long-term woodland experiment in south-eastern Australia. Australian Zoologist, 35, 633-648.

Manning, A.D., Eldridge, D.J. \& Jones, C.G. (2015) Policy implications of ecosystem engineering for multiple ecosystem benefits. In Advances in Reintroduction Biology of Australian and New Zealand Fauna (eds D.P. Armstrong, M.W. Hayward, D. Moro \& P.J. Seddon), pp. 167-184. CSIRO Publishing, Collingwood, Australia.

McClelland, P. \& Gummer, H. (2006) Reintroduction of the critically endangered Campbell Island teal Anas nesiotis to Campbell Island, New Zealand. Conservation Evidence, 3, 61-63.

McIntyre, S., Stol, J., Harvey, J., Nicholls, A.O., Campbell, M., REID, A. et al. (2010) Biomass and floristic patterns in the ground layer vegetation of box-gum grassy eucalypt woodland in Goorooyarroo and Mulligans Flat Nature Reserves, Australian Capital Territory. Cunninghamia, 11, 319-357.

Menkhorst, P. (2008) Bettongia gaimardi. In The IUCN Red List of Threatened Species v. 2012.1. Http://www.iucnredlist.org [accessed 24 July 2012].

Michel, C.L. \& Bonnet, X. (2012) Influence of body condition on reproductive output in the guinea pig. Journal of Experimental Zoology, 317, 24-31.

Mitchell, A.M., Wellicome, T.I., Brodie, D. \& Cheng, K.M. (2011) Captive-reared burrowing owls show higher site-affinity, survival, and reproductive performance when reintroduced using a soft-release. Biological Conservation, 144, 1382-1391.

Moseby, K.E., Hill, B.M. \& Lavery, T.H. (2014) Tailoring release protocols to individual species and sites: one size does not fit all. PLoS ONE, 9(6), e99753.

Parker, K.A., Dickens, M.J., Clarke, R.H. \& Lovegrove, T.G. (2012) The theory and practice of catching, holding, moving and releasing animals. In Reintroduction Biology: Integrating Science and Management (eds J.G. Ewen, D.P. Armstrong, K.A. Parker \& P.J. Seddon), pp. 105-137. Wiley-Blackwell, Oxford, UK.

Portas, T., Fletcher, D., Spratt, D., Reiss, A., Holz, P., STALDER, K. et al. (2014) Health evaluation of free-ranging eastern bettongs (Bettongia gaimardi) during translocation for reintroduction in Australia. Journal of Wildlife Diseases, 50, 210-223.

Richardson, K., Castro, I.C., Brunton, D.H. \& Armstrong, D.P. (2015) Not so soft? Delayed release reduces long-term survival in a passerine reintroduction. Oryx, 49, 535-541.

Rose, R.W. (1987) Reproductive biology of the Tasmanian bettong (Bettongia gaimardi: Macropodidae). Journal of Zoology, 212, 59-67.

Rose, R.W. (1989) Age estimation of the Tasmanian bettong (Bettongia gaimardi) (Marsupialia, Potoroidae). Wildlife Research, $16,251-261$.

Seddon, P.J. (2010) From reintroduction to assisted colonization: moving along the conservation translocation spectrum. Restoration Ecology, 18, 796-802.

Seddon, P.J., Armstrong, D.P. \& Maloney, R.F. (2007) Developing the science of reintroduction biology. Conservation Biology, 21, 303-312.
SHORT, J. (1998) The extinction of rat-kangaroos (Marsupialia: Potoroidae) in New South Wales, Australia. Biological Conservation, $86,365-377$.

Short, J., Bradshaw, S.D., Giles, J., Prince, R.I.T. \& Wilson, G.R. (1992) Reintroduction of macropods (Marsupialia: Macropodoidea) in Australia-a review. Biological Conservation, 62, 189-204.

Shorthouse, D.J., Iglesias, D., Jeffress, S., Lane, S., Mills, P., Woodbridge, G. et al. (2012) The 'making of the Mulligans FlatGoorooyarroo experimental restoration project. Ecological Management \& Restoration, 13, 112-125.

Soorae, P.S. (ed.) (2008) Global Re-introduction Perspectives: Re-introduction Case-Studies from Around the Globe. IUCN/SSC Re-introduction Specialist Group, Abu Dhabi, UAE.

Soorae, P.S. (ed.) (2010) Global Re-introduction Perspectives: Additional Case-Studies from Around the Globe. IUCN/SSC Re-introduction Specialist Group, Abu Dhabi, UAE.

Soorae, P.S. (ed.) (2011) Global Re-introduction Perspectives: 2011. More Case Studies from Around the Globe. IUCN/SSC Re-introduction Specialist Group, Gland, Switzerland, and Environment Agency-Abu Dhabi, Abu Dhabi, UAE.

Soorae, P.S. (ed.) (2013) Global Re-introduction Perspectives: 2013 Further Case-Studies from Around the Globe. IUCN/SSC Re-introduction Specialist Group, Gland, Switzerland, and Environment Agency-Abu Dhabi, Abu Dhabi, UAE.

TAYLOR, R.J. (1993a) Habitat requirements of the Tasmanian bettong (Bettongia gaimardi), a mycophagous marsupial. Wildlife Research, 20, 699-710.

TAYLOR, R.J. (1993b) Home range, nest use and activity of the Tasmanian bettong, Bettongia gaimardi. Wildlife Research, 20, 87-95.

Wanless, R.M., Cunningham, J., Hockey, P.A.R., Wanless, J., White, R.W. \& Wiseman, R. (2002) The success of a soft-release reintroduction of the flightless Aldabra rail (Dryolimnas [cuvieri] aldabranus) on Aldabra Atoll, Seychelles. Biological Conservation, 107, 203-210.

Woodford, M.H. (200o) Quarantine and Health Screening Protocols for Wildlife Prior to Translocation and Release into the Wild. Published jointly by the IUCN Species Survival Commission's Veterinary Specialist Group, Gland, Switzerland, the Office International des Epizooties (OIE), Paris, France, Care for the Wild, UK, and the European Association of Zoo and Wildlife Veterinarians, Switzerland.

\section{Biographical sketches}

WILLIAM B ATSON's research focuses on the reintroduction biology of Australian and New Zealand fauna populations. IAIN Gordon's research interests include the behaviour, ecology, management and environmental impacts of herbivore populations. He also has an interest in the practical and social aspects of ecological restoration. DONALD FLETCHER's research interests include the environmental impacts, management, conservation and ecology of native Australian macropods, and the restoration of Australian woodlands. ADRIAN MANNING's research interests incorporate many aspects of conservation biology and ecological restoration. He has a special interest in the management and restoration of Australian woodlands. 